\title{
Transient Congenital Hypothyroidism due to maternal autoimmune thyroid disease
}

\author{
Chryssanthi Mengreli ${ }^{1}$, Maria Maniati-Christidi ${ }^{2}$, Christina Kanaka-Gantenbein ${ }^{2}$, \\ Panagiotis Girginoudis ${ }^{1}$, Apostolos G. Vagenakis ${ }^{3}$, Catherine Dacou-Voutetakis ${ }^{2}$
} ${ }^{1}$ Institute of Child Health, Athens, ${ }^{2}$ First Dept. of Pediatrics, Athens University, School of Medicine, Athens,
and ${ }^{3}$ Dept. of Medicine, Division of Endocrinology, University of Patras, Patras, Greece

\begin{abstract}
The neonatal screening program for congenital hypothyroidism (CH) in Greece shows an overall incidence of the disease of 1:2321. The cases with permanent $\mathrm{CH}$ have an incidence of 1:2542, whereas the transient forms of $\mathrm{CH}$ account for $8.7 \%$ of all cases diagnosed as $\mathrm{CH}$. Transplacental passage of maternal thyrotropin receptor-blocking antibodies is a rare cause of transient CH. In our program, a retrospective analysis of 508,358 screened newborns revealed 6 infants with transient $\mathrm{CH}$ caused by maternal thyroid autoimmunity, representing $2.7 \%$ of all cases of $\mathrm{CH}$. All the newborns with transient $\mathrm{CH}$, due to maternal autoimmune thyroid disease, had high serum TSH concentration (ranging from 98 to $689 \mathrm{mU} / \mathrm{L}$ ), whereas serum thyroxine (T4) values were low normal to normal in 3 of them. Replacement therapy with L-thyroxine was initiated at a mean age of 6.5 days. The newborns with transient $\mathrm{CH}$ belonged to 4 families, one of which had 4 and another 2 children with the same pathology. Thyrotropin-receptor antibodies (TSH-R Abs), present at the initial examination in newborns' serum, had disappeared from the infants' circulation by the third month of life. One mother carried the Abs for at least 8 years during which period she delivered four babies. The diagnosis of transient $\mathrm{CH}$ should be suspected if the mother has autoimmune thyroid disease, if there are siblings with transient $\mathrm{CH}$ or if there is no need for an increase in L-thyroxine dose with advancing age. The diagnosis is very important for genetic counseling, early treatment initiation of subsequent offspring and adequate control of the mother's thyroid function during subsequent pregnancies so that any neurodevelopmental abnormality of the fetus could be avoided.
\end{abstract}

Key Words: transient congenital hypothyroidism, TSH receptor- blocking antibodies, maternal thyroid autoimmunity

Address correspondence and requests for reprints to: C. Mengreli, PhD, Department of Biochemical Laboratories, Institute of Child Health, Aghia Sophia Childrens' Hospital, Athens, Goudi 11527, Greece, e-mail: mengrelich@otenet.gr, Tel: +30 2107467790 , Fax: +30 2107700111

Received 04-12-02, Revised 09-02-03, Accepted 21-02-03

\section{INTRODUCTION}

Neonatal screening programs for congenital hypothyroidism $(\mathrm{CH})$ on a nationwide basis depict not only cases with permanent $\mathrm{CH}$ but also those with transient forms of $\mathrm{CH}$. The incidence of permanent $\mathrm{CH}$ is about 1:3000-3500 newborns and is due either to dyshormonogenesis or to thyroid gland dysgenesis (ab- 
sence, hypoplasia or ectopia of the gland). These cases require life-long substitution therapy with L-thyroxine ${ }^{1}$.

Transient $\mathrm{CH}$ is not common and is usually caused either by maternal ingestion of goitrogenic substances which reach the fetus via placental transfer (i.e. iodine, thioureas, sulphonamides etc.) or by maternal-fetal transfer of thyrotropin receptor-blocking antibodies, which are immunoglobulins of IgG type. It may also be caused by iodine deficiency or overload in the neonatal period ${ }^{2}$. Transient $\mathrm{CH}$ persists for a variable period of time postnatally and substitution therapy may be needed for a short period depending on the cause of the condition.

Epidemiological data about the true incidence of transient $\mathrm{CH}$ due to maternal thyroid autoimmunity are scarce since most published cases are isolated ${ }^{3,4}$.

The present study aims to assess the occurrence, incidence and evolution of transient $\mathrm{CH}$ caused by maternal thyroid autoimmunity.

\section{SUBJECTS AND METHODS}

A neonatal screening program for $\mathrm{CH}$ was begun in Greece in $1979^{5}$. Thyroid stimulating hormone (TSH) has been measured in dried blood spots by a RIA-TSH method. Blood is routinely obtained by heelprick on a Schleicher and Schuell 2992 filter paper between the $3^{\text {rd }}$ and $5^{\text {th }}$ day of life. When a newborn is highly suspicious for $\mathrm{CH}$ ( $\mathrm{TSH} \geq 25 \mathrm{mU} / \mathrm{L}$ ), a serum biochemical examination of thyroid function is requested. For the cohort of TSH values between 10 and $25 \mathrm{mU} / \mathrm{L}$ in whole blood, a repeat blood specimen on filter paper is required. Values of TSH below $10 \mathrm{mU} / \mathrm{L}$ in whole blood are considered normal. When a family already has a child with $\mathrm{CH}$, the next offspring is clinically and biochemically examined during the first postnatal days.

Between 1997 and 2001 a total of 508,358 newborns were screened. Two hundred fifty-seven of them were checked for anti- thyroid Abs, namely anti-thyroglobulin (anti-Tg) and anti-microsomal (anti-TPO), and for thyrotropin-receptor Abs (TSH-R Abs). These cases represent $69 \%$ of recalled newborns with spot $\mathrm{TSH}$ values $>25 \mathrm{mU} / \mathrm{L}$ in whole blood. The remaining $31 \%$ of the cases were examined only for thyroid hormones and $\mathrm{TSH}$, because they were referred for evaluation to other pediatric endocrinological units of the country and were either classified as infants with normal thyroid function or as hypothyroid. Finally $80 \%$ of the newborns with hypothyroidism were examined for Abs.

The biochemical examination of the neonates suspected for $\mathrm{CH}$ included serum measurements of thyroxine (T4), free T4, (FT4), triiodothyronine (T3), $\mathrm{TSH}$, thyroid Abs (anti-Tg and anti-TPO) and TSH$\mathrm{R}$ Abs. In mothers of babies suspected for $\mathrm{CH}$ serum values of T4,T3, TSH and anti-thyroid and TSH-R Abs were determined.

Serum T4 and T3 were determined by radioimmunoassay (RIA) while FT4 and TSH by chemiluminescence immunoassay (Nichols Advantage, Nichols Institute Diagnostics). For RIA-T4 intra- and interassay coefficient of variations (CVs) on 3 different T4 levels ranged from $3.0 \%$ to $3.9 \%$ and $4.6 \%$ to $8.5 \%$, respectively. For RIA-T3 the respective figures were $2.0 \%$ and $3.5 \%$ and $3.7 \%$ and $1.8 \%$, for $\mathrm{TSH} 2.3 \%$ and $6.0 \%$ and $14.7 \%$ and $7.0 \%$ and for FT4 $6.6 \%$ and $4.5 \%$ and $7.1 \%$ and $3.8 \%$. The thyroid Abs were measured by an immunoradiometric assay (DiaSorin Diagnostics). The CVs for anti-Tg ranged from $3.6 \%$ to $4.4 \%$ (intra-assay) and $6.7 \%$ to $11.6 \%$ (inter-assay) and for anti-TPO from $2.4 \%$ to $6.1 \%$ and $4.8 \%$ to $7.8 \%$, respectively. The TSH-R Abs determined by a radioreceptor assay produced by Incstar Corp., Stillwater, MN. This method detects Abs that interfere with the binding of TSH to TSH receptor without differentiating between thyroid-stimulating Abs and thyroid stimulation-blocking Abs. The CVs of the method ranged from $7.0 \%$ to $12.0 \%$ (intra-assay) and $8.7 \%$ to $17.7 \%$ (inter-assay).

The criteria used for the diagnosis of transient $\mathrm{CH}$ due to maternal autoimmune thyroid disease were: a) the presense of TSH-R Abs in mothers' and infants' serum, b) the disappearance of TSH-R Abs from the infants' circulation, c) normal thyroid function after treatment discontinuation and d) no requirement for adaptation of L-thyroxine dose as the infant increased in size.

\section{RESULTS}

Among the 508,358 screened newborns, 219 were found to have $\mathrm{CH}$ and replacement therapy with Lthyroxine was initiated at a mean age of 18 days. Two 
hundred of them were proved to have permanent $\mathrm{CH}$, thus yielding an incidence of the disease of 1:2542 (Table 1). The remaining 19 newborns had transient $\mathrm{CH}(8.7 \%$ of all cases diagnosed as having $\mathrm{CH})$. Six of them had transient $\mathrm{CH}$ due to maternal thyroid autoimmunity (2.7\% of $\mathrm{CH}$ cases). In the remaining 13 newborns the transient course of the disease was attributed to problems related to prematurity or perinatal complications.

In Table 2 the recalled infants, grouped according to their final diagnosis and the results of Abs measurements are listed. Sixteen of the 19 newborns with transient $\mathrm{CH}$ were checked for Abs. One of those not checked for Abs belonged to a family with 3 previous children with positive TSH-R Abs and transient $\mathrm{CH}$ and her mother had Hashimoto thyroiditis. This patient was therefore included in the group of transient $\mathrm{CH}$. The remaining two were premature newborns, part of a twin set and the twin siblings did not have thyroid function problems and therefore their transient $\mathrm{CH}$ was attributed to prematurity.

The percentage of newborns with positive anti-Tg and anti-TPO Abs is about the same in the groups of normal infants and those with permanent $\mathrm{CH}$, while the group with transient $\mathrm{CH}$ had a much higher incidence of positive anti-Tg and anti-TPO Abs (Table 2).
In Table 3 the laboratory data of the 6 cases with transient $\mathrm{CH}$ due to maternal autoimmune thyroid disease are listed. Cases 3 and 4 are siblings and there were two more older children in the family with the same course of the disease. The same is true of case 1 , who had an older sister with transient $\mathrm{CH}$. All newborns with transient $\mathrm{CH}$ presented very high TSH values on dried blood spots during the first days of life. At a mean age of 6.5 days (range 1-14 days), serum TSH concentrations ranged from 98 to $689 \mathrm{mU} / \mathrm{L}$ (normal values $<5$ ). The $\mathrm{T} 4$ values were low-normal to normal in 3 newborns and the T3 values were normal in all but one.

Antithyroid Abs were present (either one or both of them) in all newborns with transient $\mathrm{CH}$ due to maternal autoimmune thyroid disease.

Sequential measurements of the Abs in the patients' serum showed that TSH-R Abs were cleared by the second to third month of postnatal life, irrespective of their initial concentration. Antithyroid Abs needed more time for their elimination depending on their initial titre: more than 5 months for anti-Tg (case 2) and more than 8 months for anti-TPO Abs (case 6).

All infants with transient $\mathrm{CH}$ due to maternal thyroid autoimmunity were full-term and were born after an uneventful pregnancy. Their birth weight was

Table 1. Results of the Greek screening program for congenital hypothyroidism in 508,358 newborns (1997-2001).

\begin{tabular}{lcc}
\hline Diagnosis & No of patients & Incidence/percentage of cases \\
\hline Newborns with CH & 219 & $1: 2,321$ \\
a. newborns with permanent CH & 200 & $\mathbf{1 : 2 , 5 4 2}$ \\
b. newborns with transient CH & 19 & $\mathbf{8 . 7 \%}$ of CH cases \\
c. newborns with transient CH due to & 6 & $\mathbf{2 . 7 \%}$ of CH cases \\
maternal autoimmune thyroid disease & & or $\mathbf{1 : 8 4 , 7 2 6}$ newborns \\
\hline
\end{tabular}

Table 2. Data on thyroid and TSH-R Abs in newborns with transient or permanent congenital hypothyroidism and in newborns with normal thyroid function.

\begin{tabular}{|c|c|c|c|c|c|c|c|}
\hline \multirow[t]{3}{*}{ Recalled newborns } & \multirow{3}{*}{$\begin{array}{l}\text { Number of newborns } \\
\text { examined for Abs }\end{array}$} & \multicolumn{6}{|c|}{ no. of newborns with positive Abs } \\
\hline & & \multicolumn{2}{|c|}{ anti-Tg } & \multicolumn{2}{|c|}{ anti-TPO } & \multicolumn{2}{|c|}{ TSH-R Abs } \\
\hline & & no & $\%$ & no & $\%$ & no & $\%$ \\
\hline A. Newborns with $\mathrm{CH}$ & 173 & 5 & 2.9 & 24 & 13.9 & 5 & 2.9 \\
\hline a. Transient $\mathrm{CH}$ & 16 & 2 & 12.5 & 5 & 31.2 & 5 & 31.2 \\
\hline b. Permanent $\mathrm{CH}$ & 157 & 3 & 1.9 & 19 & 12.1 & - & - \\
\hline B. Normal newborns & 84 & 1 & 1.2 & 10 & 11.9 & - & - \\
\hline Total & 257 & 6 & 2.3 & 34 & 13.2 & 5 & 1.9 \\
\hline
\end{tabular}


Table 3. Laboratory data of infants with transient congenital hypothyroidism due to maternal autoimmune thyroid disease. Cases 3 and 4 are siblings.

\begin{tabular}{|c|c|c|c|c|c|c|c|c|c|c|c|}
\hline Patients & $\begin{array}{c}\text { Year of } \\
\text { diagnosis }\end{array}$ & $\begin{array}{c}\text { Age (days } \\
\text { or months) }\end{array}$ & $\begin{array}{c}\text { Spot TSH } \\
(\mathbf{m U} / \mathbf{L})\end{array}$ & $\begin{array}{c}\text { T4 } \\
(\mathrm{nmol} / \mathrm{L})\end{array}$ & $\begin{array}{c}\text { FT4 } \\
(\mathrm{pmol} / \mathrm{L})\end{array}$ & $\begin{array}{c}\text { T3 } \\
(\mathrm{nmol} / \mathrm{L})\end{array}$ & $\begin{array}{c}\text { TSH } \\
(\mathbf{m U} / \mathbf{L})\end{array}$ & $\begin{array}{c}\text { Anti-Tg } \\
(\mathbf{U} / \mathbf{m L})\end{array}$ & $\begin{array}{c}\text { Anti-TPO } \\
\text { (U/mL) }\end{array}$ & $\begin{array}{c}\text { TSH-R } \\
\operatorname{Abs}(\mathbf{U} / \mathbf{L})\end{array}$ & $\begin{array}{c}\text { Thyroid } \\
\text { U/S }\end{array}$ \\
\hline \multirow[t]{3}{*}{1} & 1997 & $1 \mathrm{~d}$ & $>125$ & 69.5 & 4.2 & ND & 388 & 84 & 62 & 403 & Normal \\
\hline & & $2 \mathrm{~m}$ & & 225.0 & 25.2 & 4.78 & 0.7 & 23 & 13 & 12 & \\
\hline & & $3 \mathrm{~m}$ & & 253.7 & 31.6 & 4.56 & 0.1 & 17 & 7 & 4 & \\
\hline \multirow[t]{4}{*}{2} & 1998 & $14 d$ & $>125$ & 28.3 & 3.5 & 1.87 & 673 & 12,540 & 1,240 & 402 & Normal \\
\hline & & $2 \mathrm{~m}$ & & 185.4 & 20.6 & 4.20 & 4.4 & 3,779 & 259 & 136 & \\
\hline & & $5 \mathrm{~m}$ & & 154.5 & 19.0 & 2.38 & 1.2 & 1,061 & 75 & $<2$ & \\
\hline & & $9 \mathrm{~m}$ & & 171.3 & 18.8 & 2.85 & 1.6 & 37 & 7 & $<2$ & \\
\hline \multirow[t]{4}{*}{3} & 1997 & $3 d$ & $>125$ & 69.5 & $\mathrm{ND}$ & $\mathrm{ND}$ & 98 & 80 & 239 & $>300$ & \\
\hline & & $1 \mathrm{~m}$ & & & & & & & & 580 & \\
\hline & & $2 \mathrm{~m}$ & & & & & & & & 360 & ND \\
\hline & & $5 \mathrm{~m}$ & & & & & & & & $<2$ & \\
\hline 4 & 2000 & $3 \mathrm{~d}$ & $>125$ & 27.0 & $\mathrm{ND}$ & 1.65 & 287 & ND & $\mathrm{ND}$ & $\mathrm{ND}$ & $\mathrm{ND}$ \\
\hline \multirow[t]{5}{*}{5} & 2000 & $9 \mathrm{~d}$ & 64 & 148.0 & 14.1 & 3.15 & 198 & 376 & 105 & 400 & Normal \\
\hline & & $1 \mathrm{~m}$ & & 118.5 & 19.0 & 2.70 & 5.7 & 157 & 69 & 190 & \\
\hline & & $2 \mathrm{~m}$ & & 148.0 & 20.5 & 4.50 & 3.4 & 27 & 23 & 8 & \\
\hline & & $4 \mathrm{~m}$ & & 167.4 & 18.7 & 3.25 & 2.4 & 10 & 14 & $<2$ & \\
\hline & & $6 \mathrm{~m}$ & & 115.9 & 17.3 & 2.74 & 2.2 & 6 & 5 & $<2$ & \\
\hline \multirow[t]{6}{*}{6} & 2000 & $9 d$ & $>125$ & 48.9 & 3.1 & 1.38 & 689 & 19 & 726 & $>405$ & Normal \\
\hline & & $1 \mathrm{~m}$ & & 118.5 & 18.8 & 3.06 & 76.0 & 10 & 598 & $>405$ & \\
\hline & & $2 \mathrm{~m}$ & & 146.8 & 23.9 & ND & 2.3 & $<4.0$ & 260 & 357 & \\
\hline & & $3 \mathrm{~m}$ & & 115.9 & 22.0 & 3.06 & 0.2 & $<4.0$ & 92 & $<2$ & \\
\hline & & $6 \mathrm{~m}$ & & 122.3 & 16.6 & 3.25 & 2.9 & 3.6 & 29 & $<2$ & \\
\hline & & $8 \mathrm{~m}$ & & 114.6 & 15.2 & 2.77 & 2.7 & 6.4 & 16 & $<2$ & \\
\hline \multicolumn{2}{|c|}{ Normal Values } & & $<10$ & $77-206$ & $9-28.3$ & $1.5-4.5$ & $0.3-5.0$ & $<100$ & $<10$ & $<10$ & \\
\hline
\end{tabular}

ND: Not done

over 3000gr. The most common clinical findings were prolonged jaundice ( $>10$ days) and large posterior fontanelle $(>0.5 \mathrm{~cm})$. No malformations were present in these patients. Thyroid ultrasound performed by 6 months of age in 4 cases showed normal size and morphology of the thyroid gland with a homogenous parenchyma and without focal abnormalities.

In Table 4 the clinical and laboratory data of the mothers are presented. All of them were hypothyroid on L-thyroxine therapy for a period of 2-8 years before the last delivery and 2 of these had more than one child with transient $\mathrm{CH}$. All were well controlled during pregnancy.

The infants received L-thyroxine replacement therapy immediately after diagnosis was established at a dose ranging from 25 to $50 \mu \mathrm{g} /$ day, which required no adaptation during the follow-up period. Since treatment discontinuation, thyroid function tests and the physical and psychomotor development of the patients have been normal.

The overall incidence of transient $\mathrm{CH}$ attributed to maternal thyroid autoimmunity in our material is $2.7 \%$ of all cases diagnosed with $\mathrm{CH}$.

\section{DISCUSSION}

The diagnosis and early treatment of infants with $\mathrm{CH}$ has been greatly facilitated by the application of neonatal mass screening programs. The administration of replacement therapy during the first days of life has resulted in normal psychomotor development 
Table 4. Clinical and laboratory data of mothers of infants with transient $\mathrm{CH}$.

\begin{tabular}{clccc}
\hline Patients & Clinical history & anti-Tg & anti-TPO & \multicolumn{2}{c}{ TSH-R Abs } \\
$(\mathbf{U} / \mathbf{m L})$ & $(\mathbf{U} / \mathbf{m L})$ & 245 \\
\hline 1 & Hypothyroid on $\mathrm{R}_{\mathrm{x}}(3)$ & 0.6 & 91 & 402 \\
2 & Hypothyroid on $\mathrm{R}_{\mathrm{x}}(3)$ & $>13,000$ & $>2,000$ & $\mathrm{ND}$ \\
3,4 & Hypothyroid on $\mathrm{R}_{\mathrm{x}}(8)$ & $\mathrm{ND}$ & 173 & 137 \\
5 & Hypothyroid on $\mathrm{R}_{\mathrm{x}}(2)$ & 731 & 988 & $>405$ \\
6 & Hypothyroid on $\mathrm{R}_{\mathrm{x}}(4)$ & 55 & $<10$ & $<10$ \\
\hline Normal values & & $<100$ & \\
\hline
\end{tabular}

ND: Not done. Numbers in parenthesis: years of therapy

of the children affected ${ }^{6,7}$. In Greece, a similar program was initiated in the early 80 's on a nationwide basis. The overall incidence of $\mathrm{CH}$ in the country is 1:2321. One in every 2542 screened newborns suffered permanent $\mathrm{CH}$, whereas the transient forms of the disease, which needed replacement therapy, accounted for $8.7 \%$ of all cases.

Transient $\mathrm{CH}$ caused by transplacental transfer of $\mathrm{TSH}-\mathrm{R}$ Abs is a relatively rare condition and epidemiological data in the literature are scarce. In our study, which comprised 508,358 screened newborns, we found 6 newborns with transient $\mathrm{CH}$ attributed to maternal Hashimoto thyroiditis. Thus, in every 84,726 newborns one has this condition. These cases represent $2.7 \%$ of all neonates with $\mathrm{CH}$ (transient and permanent). In North America, Brown et $\mathrm{al}^{8}$ found this form of transient $\mathrm{CH}$ in 1:180,000 screened newborns by measuring the TSH binding inhibitory activity in dried blood spots. This accounted for approximately $2 \%$ of $\mathrm{CH}$ cases in this study. Data from Switzerland showed an incidence of approximately 1:310,000 live newborns screened. Specifically, among 618,913 infants screened in a 16-year period, only two cases (two siblings) with transient $\mathrm{CH}$ due to maternal autoimmune thyroid disease were detected ${ }^{9}$.

The presence of TSH-R Abs only in neonates with transient $\mathrm{CH}$ provides strong evidence that these Abs are etiologically related to the hypothyroidism observed and are therefore of diagnostic value.

The antithyroid Abs also detected in this group do not seem to be responsible for the development of $\mathrm{CH}$ since they had also been found in the other two groups of children recalled who were proved to have either normal thyroid function or permanent $\mathrm{CH}$. These results are in agreement with a study done by
Dussault et al who suggested that antithyroid Abs do not play an important role in the pathogenesis of permanent $\mathrm{CH}^{10}$. In another study by Dussault et $\mathrm{al}^{11}$, it was demonstrated that the prevalence of microsomal Abs was similar in mothers of newborns with $\mathrm{CH}$ and in a control population (11.6\% and $12 \%$, respectively). In our study, we found similar results for anti-TPO Abs in newborns with permanent $\mathrm{CH}$ and those who eventually had normal thyroid function. Moreover we noticed the same percentage for anti-Tg Abs in these two groups of newborns $(1.2 \%$ and $1.9 \%$, respectively). These findings reflect the prevalence of these Abs in the general neonatal population, possibly through transplacental transfer. A higher percentage of these Abs was observed in the group of newborns with transient $\mathrm{CH}$ due to transplacental transfer of maternal TSH-R Abs.

The serum concentration of TSH-R Abs does not correlate with the severity of hypothyroidism as it is expressed by serum levels of T4, FT4 and TSH. We found that their clearance from an infant's circulation has been completed by the $3^{\text {rd }}$ month of life. In a study by Matsuura et $\mathrm{al}^{12}$, who presented data from two siblings with transient $\mathrm{CH}$ due to TSH-binding inhibitor immunoglobulins, it was found that the Abs had been cleared from children's blood by 3 months of age in one and by 10 months in the other. Because TSH-R Abs metabolism is crucial for the treatment period, their measurement is expected to help in the decision to terminate therapy with L-thyroxine.

All infants in the present study with transient $\mathrm{CH}$ of autoimmune origin were healthy and in good clinical condition when first examined. This is in contrast to descriptions from other studies where the hypothyroid infants had the typical appearance of a cretin ${ }^{12}$. We assume that this is due to well-controlled thyroid 
function of the mothers during pregnancy, which allowed an adequate thyroid hormone supply to the fetus through transplacental transfer. The most frequent signs encountered in our infants were prolonged jaundice (more than 10 days) and a posterior fontanelle greater than $0.5 \mathrm{~cm}$. A thyroid ultrasound in $4 / 6$ infants revealed normal size and morphology of the thyroid gland. Another important characteristic of our cases was that no adaptation of thyroxine dose was required as the child was growing. After treatment discontinuation, all children had completely normal thyroid function and normal neurodevelopmental outcome.

It must be emphasized that absence of the thyroid gland is reported in thyroid scintiscans performed at the time of diagnosis of $\mathrm{CH}$ in such infants ${ }^{3}$. This finding must be attributed to the presence of TSH-R blocking Abs and should not be mistaken for thyroid agenesis. In our cases, thyroid scintiscan was not carried out at diagnosis.

The early differential diagnosis of this type of $\mathrm{CH}$ is of considerable importance because it does not require lifelong treatment, which is undesirable for both children and parents. Suspicion for its existence should be raised by a mother's history of autoimmune thyroiditis and the presence of previous siblings with the same clinical course.

It is now well established that maternal thyroid function throughout pregnancy influences the neurodevelopmental outcome of the child ${ }^{13}$. Studies in which both mother and child are hypothyroid,as in areas with severe iodine deficiency ${ }^{14}$ or in TSH-R blocking Abs-induced $\mathrm{CH}^{15}$, the psychomotor development of the offspring is also impaired.

Therefore, in these families genetic counseling is very important to alert the parents to the possibility of recurrence of the disease in subsequent offspring, information which will ensure early evaluation and treatment of the newborn. Furthermore, such findings are of utmost importance for alerting physicians to control the mother's thyroid function in subsequent pregnancies in order to avoid any impairment of fetal neuronal development.

In conclusion, transient $\mathrm{CH}$ caused by maternalfetal transfer of TSH-R Abs is a rare condition, accounting for $2.7 \%$ of all cases with $\mathrm{CH}$. This form of $\mathrm{CH}$ should be suspected when a) serum TSH-R Abs are detected in the mother and/or the newborn, b) there is a history of maternal autoimmune thyroid disease, c) there are other siblings with transient $\mathrm{CH}$, and d) there is no need for an increase in L-thyroxine dose with advancing age. This diagnosis is very important for the proper management of the patient and for genetic counseling of the family.

Acknowledgments: The authors express their gratitude to Mses. Niki Vanikioti, Kiki Koutsoukou, Stella Manthou, Sophia Dakoutrou and Evanthia Rafa for their excellent technical assistance.

\section{REFERENCES}

1. La Franchi S, 1999 Congenital hypothyroidism: etiologies, diagnosis, and management. Thyroid 9: 735-740.

2. Delange F, 1998 Screening for congenital hypothyroidism used as an indicator of the degree of iodine deficiency and of its control. Thyroid 8: 1185-1192.

3. Francis G, Riley W, 1987 Congenital familial transient hypothyroidism secondary to transplacental thyrotropinblocking autoantibodies. Am J Dis Child 141: 1081-1083.

4. Pacaud D, Huot C, Gattereau A, et al, 1995 Outcome in three siblings with antibody-mediated transient congenital hypothyroidism. J Pediatr 127: 275-277.

5. Mengreli C, Kassiou K, Tsagarakis S, Pantelakis S, 1981 Neonatal screening for hypothyroidism in Greece. Eur J Pediatr 137: 185-187.

6. Komianou F, Makaronis G, Lambadaridis J, et al, 1988 Psychomotor development in congenital hypothyroidism. The Greek screening programme. Eur J Pediatr 147: 275278.

7. Van Vliet G, 1999 Neonatal hypothyroidism: treatment and outcome. Thyroid 9: 79-84.

8. Brown RS, Bellisario RL, Botero D, et al, 1996 Incidence of transient congenital hypothyroidism due to maternal thyrotropin receptor-blocking antibodies in over one million babies. J Clin Endocrinol Metab 81: 1147-1151.

9. Pasquier S, Torresani T, Werder E, Gnehm HE, 1997 Transitory neonatal hypothyroidism caused by transplacental transfer of anti-receptor antibodies of hypothyseal thyroid stimulation. Case report and estimated incidence. Schweiz Med Wochenschr 127: 1824-1828.

10. Dussault JH, Letarte J, Guyda H, et al, 1980 Lack of influence of thyroid antibodies on thyroid function in the newborn infant and on a mass screening program for congenital hypothyroidism. J Pediatr 96: 385-389.

11. Dussault JH, Fisher DA, 1999 Thyroid function in mothers of hypothyroid newborns. Obstet Gynecol 93: 15-20.

12. Matsuura N, Yamada Y, Nohara Y, et al, 1980 Familial neonatal transient hypothyroidism due to maternal TSHbinding inhibitor immunoglobulins. N Engl J Med 303: 738-741.

13. Glinoer D, 2001 Potential consequences of maternal hypothyroidism on the offspring: evidence and implications. 
Horm Res 55: 109-114.

14. Cao XY, Jiang XM, Dou ZH, et al, 1994 Timing of vulnerability of the brain to iodine deficiency in endemic cretinism. N Engl J Med 331: 1739-1744.

15. Matsuura N, Konishi J, 1990 Transient hypothyroidism in infants born to mothers with chronic thyroiditis: a nationwide study of twenty-three cases. The Transient Hypothyroidism Study Group in Japan. Endocrinol Jpn 37: 369-379.

\section{ERRATUM:}

Insulin resistance in pheochromocytoma improves more by surgical rather than by medical treatment (Vol. 2, No 1)

Address correspondence and requests for reprints to: Evanthia Diamanti-Kandarakis,

Associate Professor of Medicine, Medical School University of Athens, Fax: +30210 8130031, e-mail: akandara@otenet.gr 